\title{
APPLICATION OF NEWTONIAN NUDGING DATA ASSIMILATION METHOD IN HYDRODYNAMIC MODEL OF FLOOD FLOW IN THE LOWER BIEBRZA BASIN
}

\author{
Dorota MirosŁaW-ŚWIĄTEK \\ Department of Hydraulic Engineering, Warsaw University of Life Sciences
}

\begin{abstract}
The paper presents a 1D hydrodynamic flood flow model employing a data assimilation procedure based on Newtonian nudging. Data assimilation was used to determine correctly the upstream boundary condition defined as a discharge hydrograph. In the model developed, "nudging to individual observations" method was used. The data chosen for assimilation were water table levels recorded by a D-Diver automatic sensor installed in the river channel c. $1.5 \mathrm{~km}$ below a computational cross-section opening the analysed stretch of the river and the adjacent valley. This hydrological model of flood flow containing the data assimilation procedure is based on a one-dimensional Saint-Venant system of equations (dynamic wave model). The calculations were performed for the 2010 spring flood event at a 20-km stretch of the river and the floodplain in the upper part of the Lower Biebrza Basin. Modifying the boundary condition by using data assimilation has dramatically improved the accuracy of water table predictions during floods in the area of the Lower Biebrza Basin.
\end{abstract}

\section{INTRODUCTION}

Data assimilation (DA) is a research method widely used by meteorologists in numerical weather forecasting models and by oceanographers in sea level forecasting (Ghil et al. [5]). Generally speaking, it is a process where the current system state is determined from measurements. The basic task of data assimilation is to determine the initial condition for a numerical forecast based on the knowledge of forecasted values and on available observations of prognostic variables. The most common techniques include statistical methods (e.g., optimal interpolation (OI) or different variants of socalled Kalman filter (KF)), three-dimensional variational methods (3D-Var), and more advanced four-dimensional variational methods (4D-Var). A serious drawback in practical application of statistical methods are difficulties related to determining error covariance matrices, or, as it is in the case of $4 \mathrm{D}$-Var methods, implementing a coupling model (e.g., Bouttier and Courtier [2], Refsgaard [11]). Beside these methods, so called object methods also known as empirical methods are fairly often used in assimilation. They have been used since the 1960s in 2D and 3D problems. Similar methods in 4D forecasting models are referred to as 'nudging'. They are based on Newtonian relaxation, whose aim is to add the difference between the calculated and the observed variations of the system state to appropriate terms of the model's dynamic equations. When it comes to statistical or variational methods, they are characterized by a far simpler mathematical apparatus based on simple interpolation tech- 
niques. These methods produce satisfactory results and they do not require large computational powers (Lorenc [7]).

Since the late 1990s, data assimilation has also been employed in hydrological models describing flow and retention processes on a catchment scale. This is connected with development of measurement techniques such as remote sensing or satellite photography and a variety of electronic devices enabling large-scale monitoring of such parameters as rainfall, snow cover, soil humidity, ground surface temperature or vegetation structure. Correlating these data with spatial information systems (GIS) provides information that can be used for data assimilation in hydrological prognostic models. A wide list of literature on data assimilation in hydrological models can be found in a review study by Troch (Troch et al. [13]). The issues of data assimilation in predicting water flow in river channels are chiefly concerned with using this method to determine roughness coefficients (e.g., Ding et al. [4], Roux and Dartus [12]). In these works, Mannig coefficient was identified in 1D models by using variational methods consisting in minimising the objective function describing the difference between forecast and observation. In the study by Bélanger and Vincent [1], a 4D-Var variational method was used to assimilate the observed water table levels in a two-dimensional hydrodynamic model based on shallow water equations and allowing for a simplified model of sediment transport. Application of a much simpler 'nudging' object method for a hydrodynamic model, where measurements of water table in a river channel are used in the assimilation process, was presented by Swiatek [14]. Using statistical methods based on Kalman filter to integrate the observed water levels in the assimilation process was discussed by Madsen and Skotner [8].

\section{SIMULTANEOUS EQUATIONS}

FOR 1D GRADUALLY VARIED UNSTEADY FLOW IN AN OPEN CHANNEL

One-dimensional unsteady water flow in open channels is described by SaintVenant system of equations, often referred to as a dynamic wave model (Cunge et al. [3])

$$
\begin{gathered}
\frac{\partial Q}{\partial t}+\frac{\partial}{\partial x}\left(\frac{\beta Q^{2}}{A}\right)+g A \frac{\partial h}{\partial x}+A \frac{|Q| Q}{K^{2}}+q \frac{Q}{A}=0, \\
\frac{\partial h}{\partial t}+\frac{1}{B} \frac{\partial Q}{\partial x}=q
\end{gathered}
$$

where:

$Q$ - discharge $\left[\mathrm{m}^{3} / \mathrm{s}\right]$,

$h$ - water table elevation [m above mean sea level],

$g$ - gravitational acceleration $\left[\mathrm{m} / \mathrm{s}^{2}\right]$, 
$A$ - active cross-sectional area of the channel $\left[\mathrm{m}^{2}\right]$,

$q$ - lateral inflow $\left[\mathrm{m}^{3} / \mathrm{m} / \mathrm{s}\right]$,

$B$ - channel width at water surface,

$K$ - discharge module $\left[\mathrm{m}^{3} / \mathrm{s}\right]$,

$\beta$ - non-uniform velocity distribution effect correction factor,

$x$ - Cartesian coordinate $[\mathrm{m}]$,

$t$ - time [s].

Equation (1a) is a momentum conservation equation, while (1b) is referred to as a continuity equation. The form of so-called discharge module, found in equation (1a), in the fourth term representing friction, depends on whether the energy line drop (fall in friction) is defined by means of Manning formula or with the universal flow law (Darcy-Weisbach equation).

Solving hyperbolic differential Saint-Venant equations in supercritical flow conditions (Froude number $\mathrm{Fr}<1$ ) requires defining boundary conditions at the opening (upstream boundary condition) and closing (downstream boundary condition) crosssections of the channel stretch analysed. In the model discussed, discharge hydrograph $Q(t)$ is used as the upstream boundary condition, while the downstream boundary condition could be defined, depending on flow conditions, as a water table hydrograph $h(t)$, used in the case of a river confluence with a body of water, e.g., an estuary, bay or a lake or as a rating curve expressed as a monotonic function of water table elevation and discharge $Q(h)$ (rating curve in uniform steady motion).

Apart from defining upstream and downstream boundary conditions, solving equations (1a) and (1b) may require defining so-called inner boundary conditions when lateral inflow $q$ is incorporated in the model. This could refer to tributaries of the main watercourse assigned as concentrated or diffuse lateral inflow. In the first case, inflow discharge is defined in the immediate vicinity of a specific point in the river, while in the other one, lateral inflow is spread along a particular stretch of the river. Tributaries of rivers that flow into the analysed watercourse could be seen as concentrated lateral inflow, while diffuse lateral inflow is the term used to describe recharge from the subcatchment.

In the case of unsteady flow, boundary conditions must be supplemented with an initial condition, i.e., $h(x, t=0)$ and $Q(x, t=0)$ must be specified. For supercritical flows, the boundary condition, defined as a water table profile between the upstream and downstream sections of the river, is usually calculated by solving a gradually varied steady flow problem based on mechanical energy balance and known discharge distribution along the watercourse.

The simultaneous equations (1a) and (1b), describing unsteady water flow in open channels, are a system of non-linear hyperbolic partial differential equations, which cannot be solved analytically. In a general case, one should employ numerical methods of solving partial differential equations, which enable finding a discrete approximate solution. In the model discussed, the simultaneous equations (1a)-(1b) were solved by the 
finite element method (FEM). Due to time integration, the implicit scheme was used and the non-linear system of algebraic equations was solved by the predictor-corrector iterative method consisting in solving a time-step linearized system of equations and simultaneously correcting the solution by an iteration process (Szymkiewicz [15]).

\section{NUDGING DATA ASSIMILATION PROCEDURE IN 1D HYDRODYNAMIC MODEL}

The nudging method is based on the Newtonian relaxation idea, whose task is to supplement the appropriate terms of the model's dynamic equations with the difference between the calculated system state variables and the observed values. In this way, the forecasted state variables are "pushed" towards the observed values. In the analysis, one can use a regular observation network, both in time and space, or separate observations conducted at any point in time or space. Therefore, two nudging techniques are distinguished. The method connected with a regular observation network is known as "nudging to the analysis", while the approach connected with individual observations is called "nudging to individual observations" (Houser et al. [6]). In the former method, the observed values are interpolated to the computational grid of the model, and the following term is added to the dynamic equations of the model

$$
G \cdot W(x, y, z, t) \cdot \varepsilon(x, y, z) \cdot\left(h_{0}-h\right)
$$

where:

$G$ - nudging impact coefficient,

$W$ - weight functions,

$\varepsilon$ - measurement quality factor,

$h_{0}$ - value observed at a computational grid node,

$h$ - predicted state variable.

Coefficient $G$ defines the influence of nudging as compared to the other processes described by the model. Four-dimensional weighting function $W$ specifies its variation in space and time. Measurement quality factor $0<\varepsilon<1$ is related to the quality and distribution of observations in time and space. In "nudging to individual observations", differences between the forecast and the observations are defined at the points in space where observations are conducted and then interpolated to the computational grid of the model. In this approach, nudging assumes the following form

$$
G \frac{\sum_{i=1}^{N t} \sum_{k=1}^{N x} W_{i k}^{2}(x, y, z, t) \varepsilon_{k}(x, y, z)\left(h_{o i k}-h_{k}(t)\right)}{\sum_{i=1}^{N t} \sum_{k=1}^{N x} W_{i k}(x, y, z, t)}
$$


where:

$N_{t} \quad-$ number of observations in time,

$N_{x} \quad$ - number of observations in space,

$h_{\text {oik }}$ - locally observed value at point $k$,

$h_{k}(t)$ - value predicted from the model interpolated to point $i$ in time, and in space $(x, y, z)$ - to point $k$, where observations are conducted.

Measurement quality factor $\varepsilon$ characterizes measurement errors and their representativeness. Index $i$ refers to all the observations whose influence areas contain values predicted in the model.

Weight functions $W$ at moment $t$ and point $(x, y, z)$ are a combination of a horizontal weight function $w_{x y}$, vertical weight function $w_{z}$, and time weight function $w_{t}$,

$$
W(x, y, z, t)=w_{x y} \cdot w_{z} \cdot w_{t} .
$$

Weight functions $w_{x y}, w_{z}, w_{t}$ have been defined in the following way (Houser et al. [6])

$$
\begin{gathered}
w_{x y}=\frac{R^{2}-D^{2}}{R^{2}+D^{2}} \quad \text { for } \quad 0 \leq D \leq R ; \quad w_{x y}=0 \quad \text { for } \quad D>R ; \\
w_{z}=1-\frac{\left|z_{0}-z\right|}{R_{z}} \text { for } \quad\left|z_{0}-z\right| \leq R_{z} ; \quad w_{z}=0 \text { for }\left|z_{0}-z\right| \geq R_{z} ; \\
w_{t}=1 \quad \text { for } \quad\left|t-t_{0}\right|<\tau / 2 ; \quad w_{t}=\frac{\left(\tau-\left|t-t_{0}\right|\right)}{\tau / 2} \text { for } \tau / 2 \leq\left|t-t_{0}\right| \leq \tau ; \\
w_{t}=0 \text { for }\left|t-t_{0}\right|>\tau
\end{gathered}
$$

where:

$R$ - horizontal impact radius,

$D$ - distance of the $i$-th observation from computational grid node,

$R_{z}-$ vertical impact radius,

$z_{o}-$ vertical position of the $i$-th observation,

$z$ - vertical coordinate,

$t$ - time in the model,

$t_{0}$ - moment of the $i$-th observation,

$\tau-1 / 2$ of time range of observation impact in window function.

Figures 1-3 provide schematic presentations of time, vertical and horizontal components (formulas (7), (6), (5)) of weight function $W$, used in "nudging to individual observations". Świątek [14] presented a detailed analysis of the influence of particular "nudging" terms on the results obtained. 


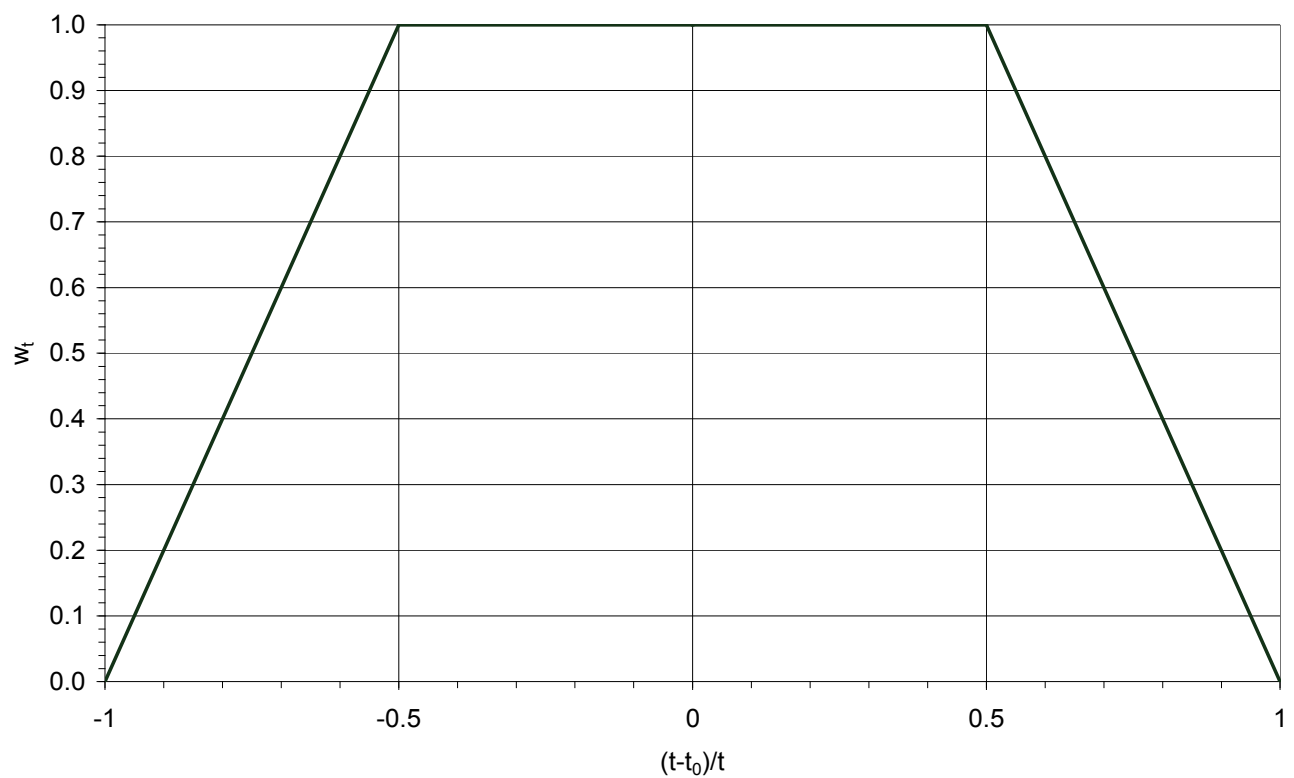

Fig. 1. Weight function $w_{t}$ in nudging

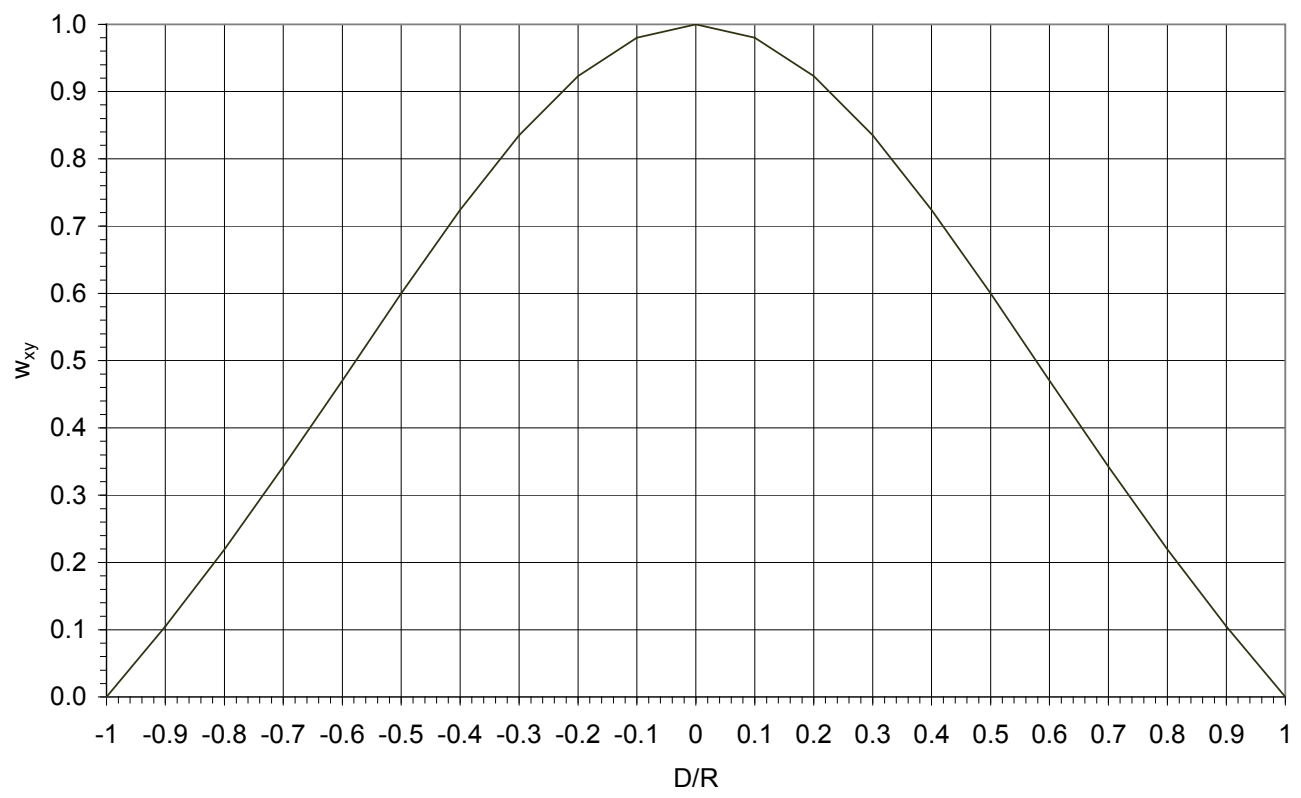

Fig. 2. Weight function $w_{x y}$ in nudging 


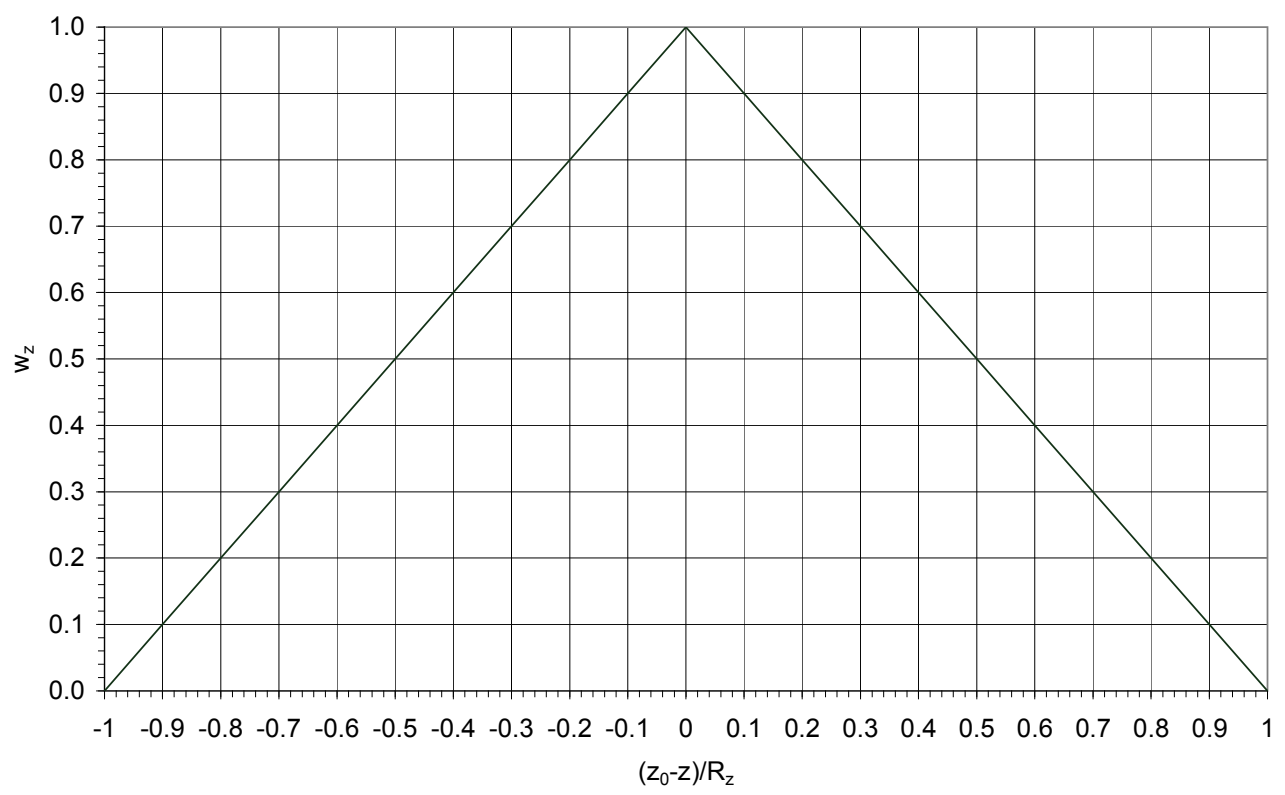

Fig. 3. Weight function $w_{z}$ in nudging

\section{NUDGING IN A NUMERICAL MODEL OF 1D FLOW IN A RIVER CHANNEL}

"Nudging to individual observations" data assimilation method was implemented in the hydrondynamic model discussed in a one-dimensional Saint-Venant system of equations described by equations (1a) and (1b), by adding term (3) to continuity equation (1b). In equation (4), a two-dimensional weight function $w_{x y}$ was replaced with a one-dimensional function $w_{x}$. Eventually, the continuity equation assumed the following form

$$
B \frac{\partial h}{\partial t}+\frac{\partial Q}{\partial x}=q+G \frac{\sum_{i=1}^{N t} \sum_{k=1}^{N x} W_{i k}^{2}(x, t) \varepsilon_{k}(x)\left(h_{o i k}-h_{k}(t)\right)}{\sum_{i=1}^{N t} \sum_{k=1}^{N x} W_{i k}(x, t)} .
$$

Employing a Galerkin FEM method to solving equation (8) produced the following equation 


$$
\sum_{j=1}^{M-1} \int_{x_{j}}^{x_{j+1}} N_{i}\left(B \frac{\partial h}{\partial t}+\frac{\partial Q}{\partial x}+G \frac{\sum_{i=1}^{N t} \sum_{k=1}^{N x} W_{i k}^{2}(x, t) \varepsilon_{k}(x)\left(h_{o i k}-h_{k}(t)\right)}{\sum_{i=1}^{N t} \sum_{k=1}^{N x} W_{i k}(x, t)}-q\right)_{e} d x=0
$$

where:

$i=1,2$,

$N_{i}$ - basis function for one-dimensional linear element (e),

$W(x, t)=w_{x} \cdot w_{t}$.

After integrating the nudging term in equation (9), the following equation was obtained

$$
\begin{aligned}
& \int_{x_{j}}^{x_{j+1}} N_{i}\left(G \frac{\sum_{i=1}^{N t} \sum_{k=1}^{N x} W_{i k}^{2}(x, t) \varepsilon_{k}(x)\left(h_{o i k}-h_{k}(t)\right)}{\sum_{i=1}^{N t} \sum_{k=1}^{N x} W_{i k}(x, t)}\right)_{e} d x \\
& =G\left(\frac{\sum_{i=1}^{N t} \sum_{k=1}^{N x} \bar{w}_{x, i k}^{2} \bar{w}_{t, i k}^{2} \varepsilon_{k}(x)\left(h_{o i k}-h_{k}(t)\right)}{\sum_{i=1}^{N t} \sum_{k=1}^{N x} \bar{w}_{x, i k} \bar{w}_{t, i k}}\right)_{e} \Delta x / 2
\end{aligned}
$$

where $\bar{w}_{x}, \bar{w}_{t}$ were calculated as mean values in element $(e)$.

\section{RESEARCH AREA}

The hydrodynamic model was developed for the Lower Biebrza Basin, which occupies the southern part of the Biebrza valley between the village Osowiec and the confluence with the Narew. The length of the southern basin is c. $30 \mathrm{~km}$ and its width varies from 12 to $15 \mathrm{~km}$. Most of this area is occupied by a fluvial terrace which contains large flat peatbogs and 1-2-km wide slightly undulating silt near-channel zone (Żurek [16]). At this section, the river channel is tortuous, forming numerous meanders, distributaries and oxbow lakes, where water flows during floods. The width of the channel varies from c. 20 to $35 \mathrm{~m}$. The channel is clearly distinguishable and in the southern part, near its confluence with the Narew, it cuts strongly into the bottom of the valley (Okruszko et al. [9]). The most important tributaries of the Biebrza in its lower course are the right-bank Klimaszewnica and Wissa and the left-bank Kosódka. The Lower Biebrza valley has a characteristic zonal pattern of vegetation, which fully 
reflects the water conditions in the analysed area. Oświt [10] distinguishes five vegetation zones in this area: reed communities Phragmition, Carex-reed communities Magnocaricion, Carex-moss communities Scheuchzerio-Caricetea fuscae, willow and birch scrubland as well as alder and birch-alder woodland communities Alnetea glutinosae.

\section{SIMULATION OF FLOOD FLOW IN THE LOWER BIEBRZA BASIN}

The 1D model was employed to perform computational flood flow simulations for the flood that occurred between 1st April and 30th June 2010. As the data which could be used for model verification and in data assimilation procedure were available only for two river Divers (DR100 and DR102), the flow area was narrowed to a river stretch between cross-sections BD1 and P39 (Fig. 4). The main task of the 1D model was to define the active parts of cross-section $\left(A_{e}\right)$ which take part in water flow. Only surface $\left(A_{e}\right)$, including the active surface of the main channel, was considered in the momentum conservation equation (equation (1a)), while the remaining surface, not taking part in the flow though filled with water, appears in the continuity equation (1b). To determine the active zones and to calibrate the model (define Manning coefficients for the channel and the floodplains), water table measurements taken on 7th April 2010 and 8th June 2010 were used.

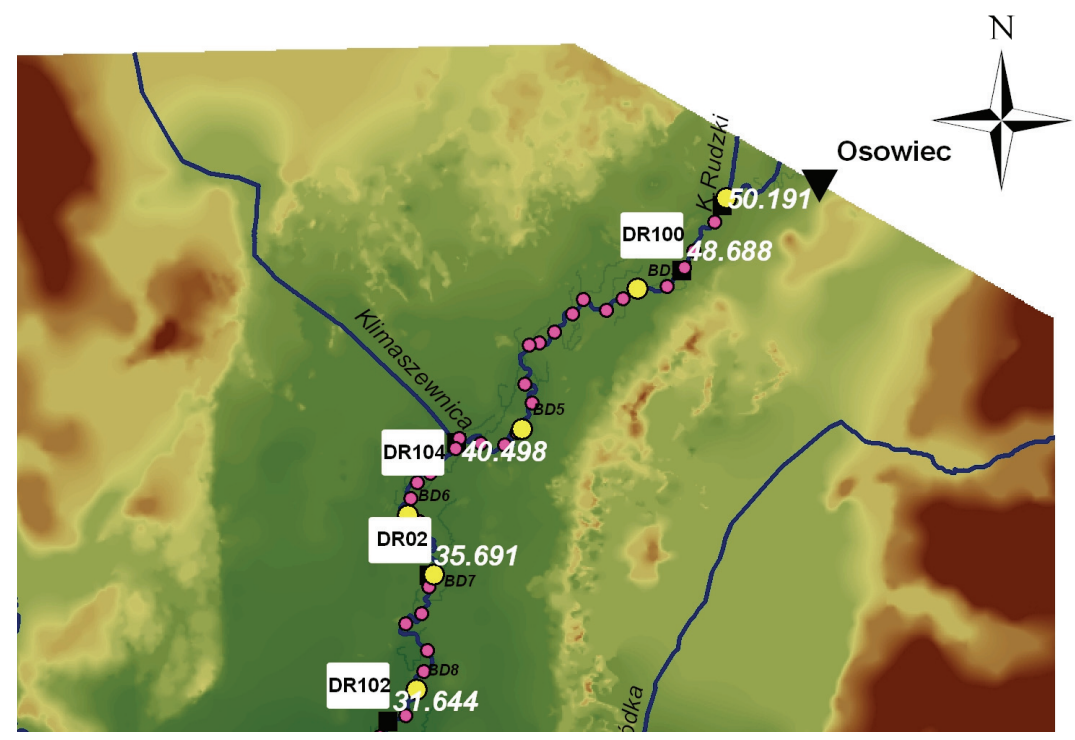

Fig. 4. Location of computational cross-sections and automatic measurement sensors in the area of the Lower Biebrza Basin 
In order to define the width of active zones and to select the value of Manning coefficient for the river channel and the floodplain, numerical experiments were conducted in such a way that the difference between the forecast from the model and the measured water table level (8th June 2010) could be the smallest. The calculations were performed for a constant boundary condition at cross-section BD1 $\left(Q=69.9 \mathrm{~m}^{3} / \mathrm{s}\right)$ while the downstream boundary condition was the water table elevation at cross-section P39 (HP39 = $104.79 \mathrm{~m}$ above mean sea level). The inflow from the subcatchment was estimated from the discharge balance for Burzyn gauge and it reached $50.86 \mathrm{~m}^{3} / \mathrm{s}$ at the stretch between cross-sections P39 and BD1. The width of active flow zones $A_{e}$ varied from 100 to $400 \mathrm{~m}$. The Manning coefficient oscillated between 0.033 and 0.040 in the river channel, and from 0.05 to 0.1 on the floodplain. The mean squared error in this case was $0.02 \mathrm{~m}$, and the maximum difference between the measured and predicted water table level $-0.03 \mathrm{~m}$.

The model elaborated in this way was used for computational simulations of the 2010 flood flow (1st April-30th June).

The upstream boundary condition in the model was the discharge hydrograph at cross-section BD1 (Fig. 5), which is the sum of discharge hydrographs for Osowiec and Przechody gauges. It is discernible that for this flood event recharging from the subcatchment was essential. At two flood peaks, the outflow from the lower basin at Burzyn gauge was almost twice as high as the inflow at cross-section BD1. In the model, the inflow from the subcatchment is estimated from discharge balances for Burzyn gauge. The downstream boundary condition is the water table level recorded by Diver DR102 interpolated for the location of cross-section P39 (Fig. 4). The model was verified with the readings from DR100 sensor.

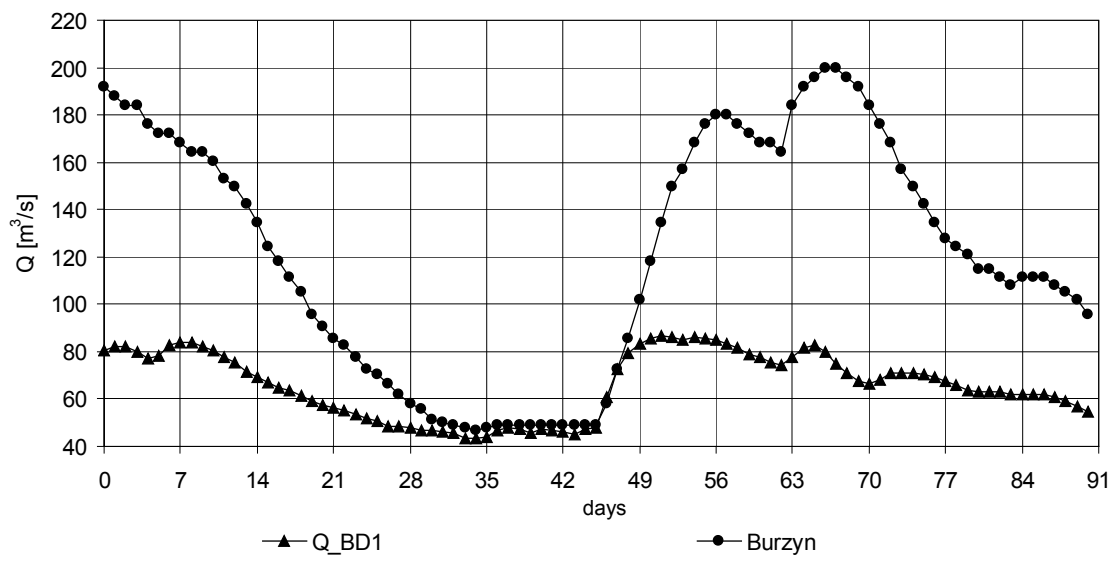

Fig. 5. Discharge hydrographs at cross-section BD1 and at Burzyn gauge (1st April-30th June 2010) 


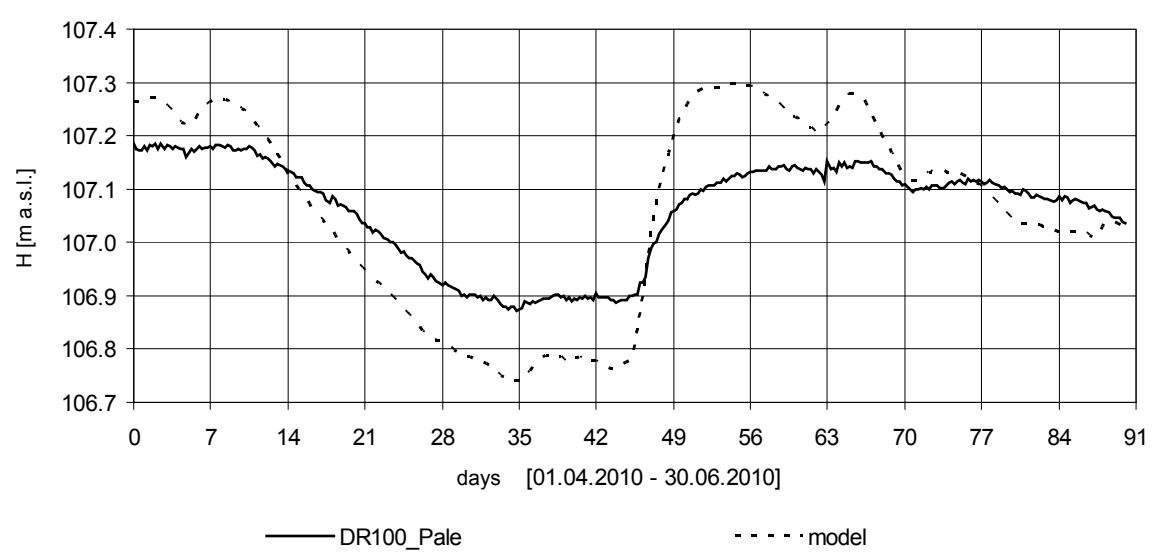

Fig. 6. Predicted water table hydrograph and the actual one, recorded by Diver DR100

Table 1 presents model errors calculated for Diver DR100. The range of changes in predicted water table elevations for Diver DR100 location is almost twice as wide as the range of DR100 readings, although the mean squared error (MSE) is $0.1 \mathrm{~m}$. The value of correlation coefficient $R$ is 0.943 . The 1D model definitely overestimates water table elevations at flood peaks and underestimates their values after the passage of the peak (Fig. 6).

Table 1

Model errors (Diver DR100)

\begin{tabular}{|l|c|c|}
\hline & DR100 & DR100_model \\
\hline$M S E[\mathrm{~m}]$ & & 0.1 \\
\hline$R$ & & 0.943 \\
\hline$H_{\max }[\mathrm{m}]$ & 107.19 & 107.30 \\
\hline$H_{\min }[\mathrm{m}]$ & 106.87 & 106.73 \\
\hline $\mathrm{dH}=H_{\max }-H_{\min }[\mathrm{m}]$ & 0.31 & 0.56 \\
\hline
\end{tabular}

The results suggest that the reason for such performance may be due to the adopted upstream boundary condition defined for the BD1 cross-section location. Diver DR100 is located $1.5 \mathrm{~km}$ below cross-section BD1 and its readings should be quite well correlated with the values at cross-section BD1.

It could be inferred from Fig. 7 that the forecasted water table level is very well correlated with the upstream boundary condition $(R=0.977)$, while DR100 readings are not so well correlated; the correlation coefficient is 0.878 in this case. Therefore, it may be concluded that the upper boundary condition defined as the sum of discharges at Osowiec and Przechody gauges is responsible for errors in the model. 


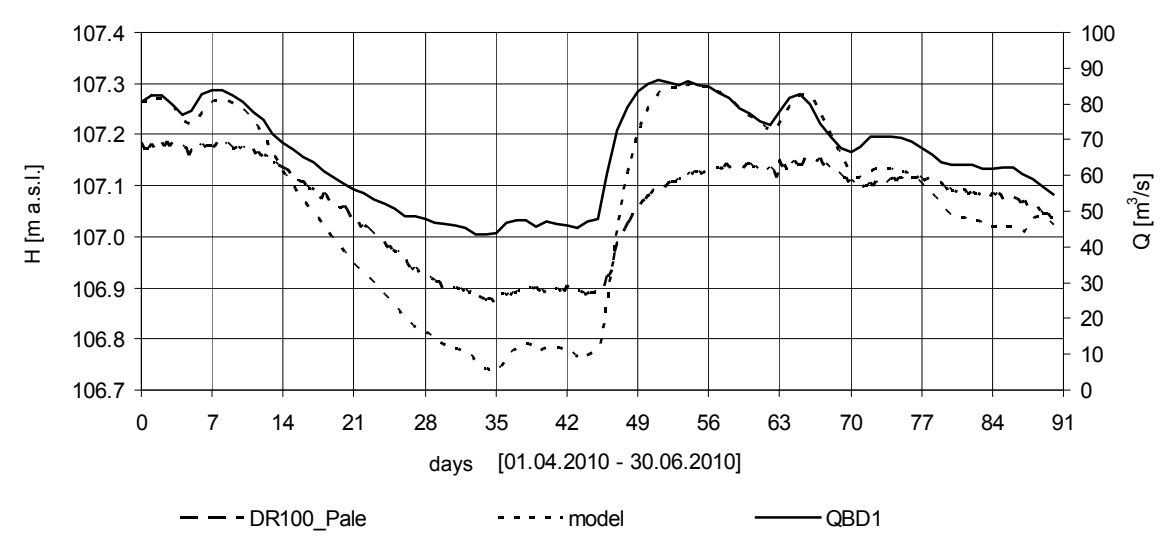

Fig. 7. Upstream boundary condition (QBD1) at cross-section BD1; observed and forecasted water table elevations at Diver DR100

\section{NUDGING-BASED FLOOD FLOW SIMULATION IN THE LOWER BIEBRZA BASIN}

In the 1D model of flood flow in the area of the Lower Biebrza Basin, nudging was employed to assimilate water table height recorded by Diver DR100 between 1st April and 30th June in the model (Fig. 4). It was assumed that measurement quality was satisfactory and therefore parameter $\varepsilon=1$. At DR100, data is collected at 6 -hour intervals. For calculations, $\tau / 2$ of 3 hours was adopted (formula (7)). It was also assumed that parameter $G$ in nudging equals 1 and radius $R$ of observation impact on water table elevations calculated at model grid nodes reaches $5000 \mathrm{~m}$. Swiatek [14] conducted a detailed analysis of the influence of particular nudging parameters on the results obtained. The use of nudging dramatically improved the model forecast at Diver DR100 location (Table 2). The errors are negligible and the model fully reflects the dynamics of water table changes at DR100 location.

Table 2

Model errors (Diver DR100, Nud $G=1, R=5000$ )

\begin{tabular}{|l|c|c|}
\hline & DR100 & DR100_model \\
\hline$M S E[\mathrm{~m}]$ & & 0.01 \\
\hline$R$ & & 0.998 \\
\hline$H_{\max }[\mathrm{m}]$ & 107.19 & 107.20 \\
\hline$H_{\min }[\mathrm{m}]$ & 106.87 & 106.86 \\
\hline $\mathrm{dH}=H_{\max }-H_{\min }[\mathrm{m}]$ & 0.31 & 0.34 \\
\hline
\end{tabular}


As Diver DR100 is situated at a small distance (c. $1.5 \mathrm{~km})$ from cross-section BD1, where the boundary condition is defined, an attempt to use nudging was made in order to improve boundary condition definition in the 1D model. In the next simulation, the predicted discharge hydrograph containing data assimilation $(G=1, R=5000)$, calculated at Diver DR100 location, was transferred to cross-section BD1 as the upstream boundary condition. This approach dramatically improved the quality of 1D hydrodynamic model without data assimilation $(\mathrm{Nud}=0)$ (Fig. 8). The MSE error decreased twofold and reached the value of $0.05 \mathrm{~m}$ (Table 3).

Table 3

Errors in 1-D model (Diver DR100, Nud $G=1, R=5000$ )

\begin{tabular}{|l|c|c|c|}
\hline & DR100 & DR100_model0 & DR100_model1 \\
\hline$M S E[\mathrm{~m}]$ & & 0.10 & 0.05 \\
\hline$R$ & & 0.943 & 0.996 \\
\hline$H_{\max }[\mathrm{m}]$ & 107.19 & 107.30 & 107.26 \\
\hline$H_{\min }[\mathrm{m}]$ & 106.87 & 106.73 & 106.82 \\
\hline $\mathrm{dH}=H_{\max }-H_{\min }[\mathrm{m}]$ & 0.31 & 0.56 & 0.43 \\
\hline
\end{tabular}

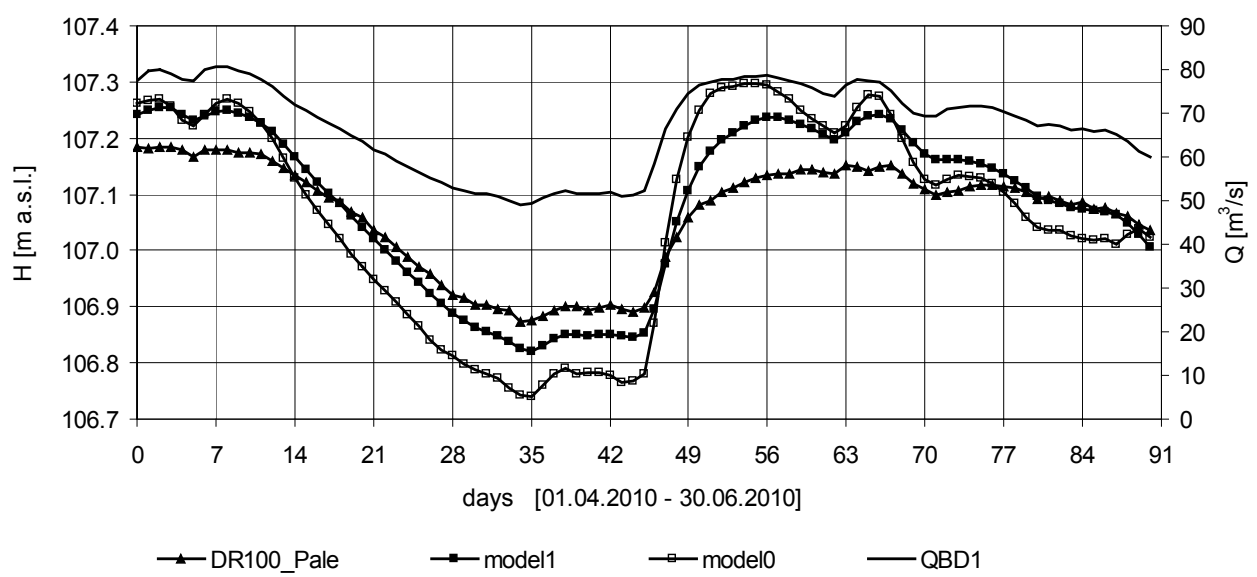

Fig. 8. Discharge hydrographs at Diver DR100 location (QBD1 - upstream boundary condition defined from data assimilation $\mathrm{Nud} G=1, R=5000$, model 0 - upstream boundary condition, hydrological data, model 1 - upstream boundary condition defined from data assimilation)

\section{CONCLUSIONS}

The 1D hydrodynamic model of flood flow at the analysed 20-km stretch of the river and its floodplain in the area of the Lower Biebrza Basin significantly overesti- 
mates water table elevation at flood peaks and underestimates these values after the passage of the peak. The range of changes in the forecasted water table elevations is almost twice as wide as the range of changes in the observed water table. The main reason for these discrepancies is the estimation of the upstream boundary condition and the inflow from the subcatchment.

The analysis of data recorded by the Diver placed upstream has demonstrated that defining the upstream boundary condition in the model as the sum of discharge hydroghraphs for Osowiec and Przechody gauges is incorrect in this case.

The nudging-based assimilation of water table level implemented in the 1-dimensional hydrodynamic model enables assimilation of water table measurements.

Employing data assimilation dramatically improves the accuracy of predicting water table levels during floods in the area of the Lower Biebrza Basin.

The numerical experiments with data assimilation by nudging have demonstrated that it could be used to define correctly the upstream boundary condition assigned in the form of discharge hydrographs.

Modifying the boundary condition as a result of using data assimilation has vastly improved the accuracy of forecasting water table levels during floods in the area of the Lower Biebrza Basin.

\section{ACKNOWLEDGEMENTS}

The research described in this article was conducted within the framework of a grant from the Ministry of Science and Higher Education of Poland No. N306 291735.

\section{REFERENCES}

[1] Bélanger E., Vincent A., Data assimilation (4D-VAR) to forecast flood in shallow-waters with sediment erosion, Journal of Hydrology, 2005, 300(1-4), 114-125.

[2] Bouttier F., Courtier P., Data assimilation concepts and methods, Meteorological Training Course Lecture Series, ECMWF, 1999.

[3] Cunge J.A., Holly F.M., Verwey A., Practical aspect of computational river hydraulics, Pitman Publishing, London, 1980, 420 pp.

[4] Ding Y., JiA Y., WANG S.S.Y., Identification of Manning's roughness coefficients in shallow water flows, Journal of Hydraulic Engineering, 2004, 130(6), 501-510.

[5] Ghil M., Ide K., Bennett A., Courtier P., Kimoto M., Nagata M., Saiki M., Sato N. (eds.), Data Assimilation in Meteorology and Oceanography, Theory and Practice, 1997.

[6] Houser P.R., Shuttleworth W.J., Famiglietti J.S., Gupta H.V., Syed K.H., Goodrich D.C., Integration of soil moisture sensing and hydrologic modeling using data assimilation, Water Resources Research, 1998, Vol. 34, No. 12, 3405-3420.

[7] LoRENC A., Analysis methods for numerical weather prediction, Quart. J. Roy. Meteor. Soc., 1986, $112,1177-1194$.

[8] MAdSEn H., SKotner C., Adaptive state updating in real time river flow forecasting - A combined filtering and error forecasting procedure, J. Hydrology. 2004. 
[9] Okruszko T., Wasilewicz M., Dembek W., Rycharski M., Matuszkiewicz A., Analiza zmian warunków wodnych, szaty roślinnej $i$ gleb bagna Lawki $w$ dolinie Biebrzy, Woda - Środowisko - Obszary Wiejskie, 2003, t. 3, z. 1(7).

[10] OŚwit J., Roślinność i siedliska zabagnionych dolin rzecznych na tle warunków wodnych, Rocz. Nauk Rol., 221, Wyd. Nauk. PWN, 1991, 229.

[11] RefSGAARD J.C., Validation and intercomparison of different updating procedures for real-time forecasting, Nordic Hydrology, 1997, 28, 65-84.

[12] Roux H., Dartus D., Data assimilation applied to hydraulic parameter identification, [in:] British hydrological society international conference 2004, Hydrology: Science and Practice for the 21st century, London, United Kingdom, 2004, 354-361.

[13] Troch P.A., Paniconi C., McLaughlin D., Catchment-scale hydrological modeling and data assimilation, Advances in Water Resources, 2003, 26, 131-135.

[14] ŚwiĄTEK D., The Data Assimilation for Unsteady 1D Open Channel Flow Model, 33rd IAHR Congress Proceedings Water Engineering for a Sustainable Environment, Vancouver, 9-14.08.2009.

[15] SzYMkiewicz R., Modelowanie matematyczne przeplywów w rzekach i kanałach, PWN, Warszawa 2000.

[16] ŻuREK S., Geomorfologia Pradoliny Biebrzy, [in:] Bagna Biebrzańskie, Zesz. Prob. Post. Nauk Rol., 1991, z. 372. 